\title{
Influence of radiation damage on strontium and iodine diffusion in silicon carbide
}

\author{
E. Friedland*, N.G. van der Berg, J.B. Malherbe \\ Physics Department, University of Pretoria, Pretoria, South Africa \\ E. Wendler, W. Wesch \\ Institut für Festkörperphysik, Friedrich-Schiller Universität Jena, Germany
}

\begin{abstract}
.
The transport behaviour of strontium and iodine through single and poly crystalline $\mathrm{SiC}$ wafers was investigated using ion beam analysis and electron microscopy. Fluences of $2 \times 10^{16} \mathrm{Sr}^{+} \mathrm{cm}^{-2}$ and $1 \times 10^{16} \mathrm{I}^{+} \mathrm{cm}^{-2}$ were implanted at temperatures between $23{ }^{\circ} \mathrm{C}$ and $600{ }^{\circ} \mathrm{C}$ with an energy of $360 \mathrm{keV}$, producing an atomic density of approximately $1.5 \%$ at the projected ranges of about $120 \mathrm{~nm}$ and $90 \mathrm{~nm}$ respectively. The broadening of the implantation profiles and its dependence on implantation parameters was determined by isochronal and isothermal annealing studies at temperatures up to $1400{ }^{\circ} \mathrm{C}$. The strong influence of radiation damage on diffusion after room temperature implantations was observed in all cases during the initial annealing stages at $1000{ }^{\circ} \mathrm{C}$. This is a result of the highly disordered crystal lattice, which re-crystallizes at this temperature. In hot implantations this effect is largely reduced but an additional transient diffusion process was observed at $1400{ }^{\circ} \mathrm{C}$ for strontium, which is related to defect annealing. Impurity trapping by extended defects is obviously an important effect. Volume diffusion is below our detection limit of $10^{-21} \mathrm{~m}^{2} \mathrm{~s}^{-1}$ for both diffusors. Hence, grain boundary diffusion is responsible for the observed iodine transport in $\mathrm{CVD}-\mathrm{SiC}$ at $1300{ }^{\circ} \mathrm{C}$, while no significant diffusion of strontium was detected at $1400^{\circ} \mathrm{C}$.
\end{abstract}

\section{Introduction}

Fuel particles of modern high-temperature nuclear reactors (HTR's) are encapsulated by CVD-layers which serve as barriers to prevent fission product release. Recent reactor designs generally make use of fuel kernels surrounded by four successive layers of low-density pyrocarbon, high-density pyrocarbon, silicon carbide and high-density pyrocarbon, with silicon carbide being the main barrier for the metallic species. These so-called TRISO fuel particles retain quite effectively most of the important fission products up to temperatures of $1000{ }^{\circ} \mathrm{C}$ [1]. Currently design studies for HTR's operating at temperatures significantly above $1000{ }^{\circ} \mathrm{C}$ are under way to enhance their efficiency, especially in view of process heat applications for hydrogen generation [2]. However, little reliable information on transport properties above this temperature is available.

Radio-active isotopes of strontium and iodine, especially ${ }^{89} \mathrm{Sr}\left(\mathrm{T}_{1 / 2}=50.5 \mathrm{~h}\right),{ }^{90} \mathrm{Sr}\left(\mathrm{T}_{1 / 2}=\right.$ $26.5 \mathrm{y}),{ }^{129} \mathrm{I}\left(\mathrm{T}_{1 / 2}=15.7 \times 10^{6} \mathrm{y}\right)$ and ${ }^{131} \mathrm{I}\left(\mathrm{T}_{1 / 2}=8 \mathrm{~d}\right)$, are important fission products and of radio-ecological relevance because of their possible accumulation in the human body. Strontium is due to its chemical similarity to calcium easily deposited in bones, while iodine is absorbed

$\overline{\text { "Corresponding author. E mail: erich.friedland@up.ac.za }}$ 
in the thyroid gland with a biological half-life of approximately 140 days. In recent studies on iodine diffusion in silicon carbide, extremely low diffusion coefficients were observed at temperatures up to $1000{ }^{\circ} \mathrm{C}[3,4]$. However, at $1200{ }^{\circ} \mathrm{C}$ diffusion increased dramatically in highly disordered silicon carbide obtained by room temperature implantation, while very little iodine was lost through the surface [4]. This is indicative of a transport process related to chemical reactions between iodine and silicon carbide in this temperature region. Electron microscopic investigations revealed a drastic change of the surface topography between $1100{ }^{\circ} \mathrm{C}$ and 1200 ${ }^{\circ} \mathrm{C}$, which is not observed with un-implanted $\mathrm{SiC}$ wafers at even much higher temperatures. In this work diffusion properties of strontium are investigated, while those of iodine are revisited with special emphasis on hot implanted single and polycrystalline samples.

\section{Experiment and analysis}

Hexagonal 6H-SiC from Intrinsic Semiconductors ${ }^{\circledR}$ and CVD-SiC from Valley Design Corporation $^{\circledR}$, having a columnar structure of mainly 3C-SiC crystallites, were used in this investigation. Into the wafers $360 \mathrm{keV}$ ions were implanted at temperatures ranging from room temperature (RT) to $600{ }^{\circ} \mathrm{C}$ with a fluence of either $2 \times 10^{16} \mathrm{Sr}^{+} \mathrm{cm}^{-2}$ or $1 \times 10^{16} \mathrm{I}^{+} \mathrm{cm}^{-2}$ and a flux not exceeding $10^{13} \mathrm{~cm}^{-2} \mathrm{~s}^{-1}$. According to simulations employing the TRIM-98 code [5] and assuming displacement energies of $35 \mathrm{eV}$ for the silicon and $20 \mathrm{eV}$ for the carbon atoms [6], the above fluences introduce displacement damages of $\sim 40 \mathrm{dpa}$ at $88 \mathrm{~nm}$ and $~ 30 \mathrm{dpa}$ at 70 $\mathrm{nm}$ respectively. The different implantation temperatures made it possible to compare the evolution of transport processes in initially amorphous and crystalline silicon carbide. A detailed description of the experimental techniques used is given elsewhere [4].

To investigate the diffusion behaviour isochronal and isothermal annealing studies were performed. Fick's diffusion equation for the dilute limit leads to a particularly simple solution if the original profile at time $t_{0}=0$ can be described by a Gaussian distribution [7]. In that case the concentration profile after annealing for a time $t$ stays a normal distribution in an infinite medium and is given by

$$
C(x, t)=K[\pi D t]^{-1 / 2} \exp \left(-x^{2} / 4 D t\right)
$$

In this equation $K$ is an adjustable constant, while the position of the maximum concentration is unchanged at $x=0$. Defining the profile width $W(t)$ as the full width at half maximum (FWHM), the following relationship between the final and original widths holds:

$$
[W(t)]^{2}=4 D t \ln (2)+[W(0)]^{2} .
$$

Hence, the diffusion coefficient $D$ is directly obtained from the slope of a plot of $[W(t)]^{2}$ versus annealing time at constant temperature.

The as-implanted depth profiles at room and high temperatures display approximately a normal distribution. However, an increasing asymmetry is observed after high-temperature annealing when the diffusing atoms reach the surface. In order to exclude this surface effect from the analysis only data for depths of $d>60 \mathrm{~nm}$ are fitted to a Gaussian function. This exclusion also insures that the result is mainly determined by diffusion in the less damaged tail 
region of the distribution. As the shapes of the implantation profiles are nearly Gaussian in the peak region, this additional approximation should still allow an analysis in terms of the procedure discussed above without introducing too large uncertainties.

\section{Results and discussion}

Fig. 1 depicts $\alpha$-particle RBS-channeling spectra of strontium implantations in single crystalline samples at different temperatures, showing the well-known radiation hardness of $\mathrm{SiC}$ above $300{ }^{\circ} \mathrm{C}[8,9]$. It leaves the crystal structure intact if implanted above that temperature, although high densities of extended defects are present, which leads to the strong damage peaks in the aligned spectra. Similar spectra are obtained for the iodine implants (not shown). They reveal in both cases complete amorphization of the surface regions up to depths of $\sim 240$ $\mathrm{nm}$ and $\sim 225 \mathrm{~nm}$ respectively for the strontium and iodine implants at RT. These highly disordered surface regions re-grow only partly epitaxially from the bulk during high temperature annealing, as simultaneously re-crystallization leads to the formation of a poly-crystalline phase. Typically a $150 \mathrm{~nm}$ thick poly-crystalline surface region remains after prolonged annealing at $1200{ }^{\circ} \mathrm{C}$. Similar damage profiles as observed in the single crystals after ion implantation can be expected for CVD samples. Grain boundaries should only play a secondary role in defect creation, as the ions' projected range is relatively small compared to the average size of the crystallites. Even smaller are the average sizes of collision cascades responsible for radiation damage. Hence, most collision cascades are embedded within a single crystallite.

Fig. 2 shows strontium and iodine depth profiles in $6 \mathrm{H}-\mathrm{SiC}$ for implantations at RT and 600 ${ }^{\circ} \mathrm{C}$. The first four statistical moments as obtained by fitting the data to an Edgeworth distribution are given in the text boxes. In both cases range straggling is larger for the higher temperature, indicating a significant temperature dependence of irradiation induced diffusion. Also plotted are TRIM simulations, which agree reasonably well with the experimental data as far as ion ranges are concerned, but predict much smaller values for range straggling $\sigma$. In view of the many approximations, especially the neglect of defect recombination and thermal contributions, this is not surprising.

\subsection{Strontium transport}

Fig. 3 displays profile widths of strontium implants at RT into single crystalline and at 600 ${ }^{\circ} \mathrm{C}$ into poly-crystalline silicon carbide after isochronal annealing for 5 hours at temperatures between $1000{ }^{\circ} \mathrm{C}$ and $1400{ }^{\circ} \mathrm{C}$. The cold implant into $6 \mathrm{H}-\mathrm{SiC}$ reveals strong diffusion during the first annealing step at $1000^{\circ} \mathrm{C}$. Most of it can probably be assigned to forward diffusion in amorphous silicon carbide, in which initially the implanted material is completely embedded. The strong surface peak of strontium visible in Fig 4 after the first annealing cycle, which corresponds approximately to an atomic layer, confirms this assumption. This peak disappears due to sublimation during the next annealing step at $1100{ }^{\circ} \mathrm{C}$ accompanied by further profile broadening. Above $1200^{\circ} \mathrm{C}$ strontium loss is significant and Gaussian analysis becomes unreliable. However, even at $1400{ }^{\circ} \mathrm{C}$ diffusion into the undamaged bulk seems to be negligible. In this temperature region the observed strontium transport is obviously only due to processes occurring in radiation damaged material, while volume diffusion into the deeper laying un- 
damaged crystal structure is below our detection limit. In contrast to the behaviour discussed above, the hot implant into CVD-SiC shows very little strontium transport up to $1200{ }^{\circ} \mathrm{C}$. Although the irradiation induced defect density is relatively high, diffusion in poly-crystalline matter at this temperature is extremely weak. Only above $1300{ }^{\circ} \mathrm{C}$ a significant width broadening occurs. This, however, is only a transient effect, which stops after a few hours isothermal annealing. A possible explanation of this phenomenon will be discussed below.

In order to obtain information on the magnitude of diffusion processes, isothermal annealing curves were determined at different temperatures of which some are shown in Fig. 5. Fig. 5A illustrates the results for strontium implants into $6 \mathrm{H}-\mathrm{SiC}$ at $1200{ }^{\circ} \mathrm{C}$. For the RT implants strong diffusion is detected during the first annealing cycle of 5 hours, during which time significant defect restructuring takes place. However, further heat treatment at the same temperature for a total time of 40 hours does not result in any additional profile broadening. Much less diffusion occurs during the first annealing cycle in the hot implants, but also no further width broadening is obtained by prolonging the annealing time. After the initial annealing cycle the diffusion coefficient at $1200{ }^{\circ} \mathrm{C}$ is below our detection limit of approximately $10^{-21} \mathrm{~m}^{2} \mathrm{~s}^{-1}$ in both cases. In Fig. 5B isothermal annealing curves are plotted for CVD-SiC samples for different implantation and annealing temperatures. Again a substantial increase of the profile width occurs in the samples implanted at RT and annealed at $1000^{\circ} \mathrm{C}$. This is to be expected as in both cases the surface region is amorphized during the cold implantation. The observed increase of the width is somewhat smaller because of the lower annealing temperature. Prolonged annealing at $1000{ }^{\circ} \mathrm{C}$ does not show any further broadening within experimental uncertainty. CVDwafers implanted at $600 \mathrm{C}$ show also similar characteristics as the single crystals during the first annealing cycle. As far as diffusion coefficients are concerned, the uncertainties for the data at $1000{ }^{\circ} \mathrm{C}$ and $1200{ }^{\circ} \mathrm{C}$ are too large to state a definite result, indicating a value below or near $10^{-21} \mathrm{~m}^{2} \mathrm{~s}^{-1}$. Isochronal annealing depicted in Fig. 3 reveals a significant increase of the profile width between $1200{ }^{\circ} \mathrm{C}$ and $1400{ }^{\circ} \mathrm{C}$. An equivalent increase is also shown during the first 10 hours of isothermal annealing at $1400{ }^{\circ} \mathrm{C}$. However, no additional broadening occurs during further annealing up to 60 hours. It appears that diffusion processes of strontium in silicon carbide are only taking place during periods of defect annealing and stop as soon as defect restructuring is coming to an end. This indicates a process where strontium bound to defect complexes is released during their annihilation or restructuring, but is again trapped after some time by more stable defects.

Fig. 6 displays SEM images of CVD-SiC wafers implanted at different temperatures. At the top (a) an image is shown of an implant at $600{ }^{\circ} \mathrm{C}$ after 5 hours annealing at $1200{ }^{\circ} \mathrm{C}$ with the original poly crystalline structure still present. This does not change even after prolonged annealing. The image in the middle (b) shows the surface of a RT implant after 5 hours annealing at $1000{ }^{\circ} \mathrm{C}$, displaying a finely grained surface structure formed by re-crystallization of the amorphized implantation zone. From images with larger magnification grain sizes between 10 and $50 \mathrm{~nm}$ are extracted, which is significantly smaller than those observed in Fig. 6a.. Similar images are also obtained from RT implanted $6 \mathrm{H}-\mathrm{SiC}$. During prolonged annealing larger crystals grow on the surface of the RT implants as illustrated at the bottom (c), showing the surface after 60 hours annealing at $1200{ }^{\circ} \mathrm{C}$. 


\subsection{Iodine transport}

Room temperature implanted samples were subjected to isochronal annealing cycles of 5 hours each, starting at $900{ }^{\circ} \mathrm{C}$ and increasing the temperature between each cycle by $100{ }^{\circ} \mathrm{C}$ up to $1300{ }^{\circ} \mathrm{C}$. Fig. 7 displays the depth profiles of iodine implants at RT into single and polycrystalline silicon carbide at annealing temperatures between $1000{ }^{\circ} \mathrm{C}$ and $1300{ }^{\circ} \mathrm{C}$. Up to 1100 ${ }^{\circ} \mathrm{C}$ very little change of the depth distribution is observed. The first measurable broadening of the implantation profile was observed at $1200^{\circ} \mathrm{C}$, when significant diffusion towards the surface occurs in both samples. At this temperature also backward diffusion is visible in the polycrystalline sample, while this does not occur in $6 \mathrm{H}-\mathrm{SiC}$ even at $1300{ }^{\circ} \mathrm{C}$. As iodine transport becomes observable between $1100{ }^{\circ} \mathrm{C}$ and $1200{ }^{\circ} \mathrm{C}$, isothermal annealing curves were determined at these two temperatures and are displayed in Fig. 8. Diffusion coefficients were determined from the slopes, excluding the initially enhanced diffusion rate where radiation damage effects are present. At $1100{ }^{\circ} \mathrm{C}$ the slopes for the single and poly crystalline samples are zero within experimental error, from which an upper limit of the diffusion coefficient of $D \leq 10^{-21} \mathrm{~m}^{2} \mathrm{~s}^{-1}$.is obtained. At $1200{ }^{\circ} \mathrm{C}$ a sudden increase is observed in both cases. In $6 \mathrm{H}-\mathrm{SiC}$ a diffusion coefficient of $(2.6 \pm 0.4) \times 10^{-20} \mathrm{~m}^{2} \mathrm{~s}^{-1}$ is calculated, while a value of $(6.0 \pm 0.7) \times 10^{-20} \mathrm{~m}^{2} \mathrm{~s}^{-1}$ is found for CVD-SiC.

The observed huge increase of more than one order of magnitude within an interval of $100 \mathrm{~K}$ is difficult to explain by Fickian diffusion and indicates that a different transport mechanism becomes effective at this temperature. Our previous iodine retention studies [4] also support this presumption. In that work no iodine loss was observed after annealing for 60 hours at $1100{ }^{\circ} \mathrm{C}$. At $1200{ }^{\circ} \mathrm{C}$ iodine loss became apparent after 15 hours and reached values of about $10 \%$ after 60 hours in both the single and poly crystalline samples. This loss is much smaller than expected from the extreme broadening of the iodine profiles, especially in CVD-SiC, which should release a much larger portion of iodine from the surface. The apparent inhibition of iodine evaporation from the surface in combination with the preferred diffusion in this direction causes a pile-up effect and a corresponding shift of the maximum towards the surface.

In contrast to the above results obtained with RT implants, those implanted at $600{ }^{\circ} \mathrm{C}$ reveal a completely different behaviour. In $6 \mathrm{H}-\mathrm{SiC}$ iodine diffusion is barely visible after annealing for 5 hours at $1300{ }^{\circ} \mathrm{C}$ (not shown), while in CVD-SiC a relative modest diffusion towards the surface is visible in Fig. 9 with almost no backward diffusion. The slopes of the isothermal annealing curves depicted in Fig. 10 show initially an enhanced broadening rate of the depth distributions, which is significantly reduced after prolonged annealing. This indicates that extended defects still present after hot implantations have a significant influence on the diffusion rate. During annealing these defects are further reduced or modified to form structures less favourable for iodine diffusion. At $1200{ }^{\circ} \mathrm{C}$ this transition is reached at a time somewhere between 5 and 30 hours, while at $1300{ }^{\circ} \mathrm{C}$ this state is already obtained before 5 hours. The final slopes for single and poly crystalline samples at $1200{ }^{\circ} \mathrm{C}$ are nearly identical and approximately zero within experimental error. At this temperature the diffusion coefficients are obviously below our detection limit of about $10^{-}$ ${ }^{21} \mathrm{~m}^{2} \mathrm{~s}^{-1}$. At $1300{ }^{\circ} \mathrm{C}$ a diffusion coefficient of $(7 \pm 1) 10^{-21} \mathrm{~m}^{2} \mathrm{~s}^{-1}$ is extracted for CVD-SiC, while it is still undetectable for $6 \mathrm{H}-\mathrm{SiC}$. From this follows that iodine diffusion in CVD-SiC is mainly due to grain boundary diffusion. Less than $10 \%$ of the iodine is lost after 60 hours annealing at 1300 ${ }^{\circ} \mathrm{C}$, of which most occurs already within the first few hours as is evident from Fig. 9. 
Scanning electron microscopic investigations of samples implanted at room temperature and at $600{ }^{\circ} \mathrm{C}$ respectively after annealing for 5 hours at $1300{ }^{\circ} \mathrm{C}$, reveal dramatic topographical modifications in the case of room temperature implants [10]. Numerous small facetted crystals have grown on the surface with deep cavities between them, which increase in depth and size during further annealing. A similar change of topography at a smaller rate is also observed after annealing at $1200{ }^{\circ} \mathrm{C}$. The area covered by these cavities and their average depth is relatively large and hence a significant fraction of the implanted iodine should have been exposed to the sample surface, where it could have evaporated. This is obviously not the case, which points to a chemical reaction binding the iodine to the silicon carbide lattice. The observed surface structure after prolonged high temperature annealing is very similar to those of iodine implanted single crystalline samples [4]. In contrast to this behaviour the high temperature implants exhibit the original polycrystalline structure, which does not change even after 60 hours annealing at $1300{ }^{\circ} \mathrm{C}$. The explanation of the striking differences between cold and hot implantations is most probably in terms of binding energies. In the latter case the bonding of silicon and carbon to the crystal lattice is strong enough to prevent chemical reactions with iodine, which seems not to be true in the amorphous phase obtained after room temperature implantation.

\section{Conclusions}

Strontium diffusion after high temperature implantation is only observed during the initial stages of annealing, while normal Fickian diffusion of iodine is observed in CVD-SiC. In all cases an enhanced diffusion is initially observed, which is either related to phase changes or defect annealing.

Volume and grain boundary diffusion of strontium up to temperatures of $1400{ }^{\circ} \mathrm{C}$ in high temperature implants could not be detected during prolonged isothermal annealing, leading to an upper limit of about $\mathrm{D} \sim 10^{-21} \mathrm{~m}^{2} \mathrm{~s}^{-1}$. This is in agreement with but many orders smaller than the value of $\mathrm{D}<5 \times 10^{-17} \mathrm{~m}^{2} \mathrm{~s}^{-1}$ obtained by Ref. [11] from release studies measuring the breakthrough time of strontium from fuel kernels encapsulated by $\mathrm{SiC}$ layers. However, relatively strong diffusion is observed in cold implants above $1000{ }^{\circ} \mathrm{C}$ and in the initial stage of isothermal annealing of hot implants at $1400{ }^{\circ} \mathrm{C}$. As the latter stops after a few hours, it seems to be related to defect annealing processes, which release trapped strontium from defect complexes into the crystal structure, where they are again captured after some time by more stable defects.

Iodine transport in cold implants shows an abnormally large increase at $1200{ }^{\circ} \mathrm{C}$, which is difficult to explain by Fickian diffusion. As profound topographical changes of the surface occur simultaneously with no corresponding large iodine loss, a chemical reaction binding it to the highly disordered crystal structure seems to be a likely explanation. In contrast to this, normal diffusion behaviour is observed in hot implants, where the original crystal structure is preserved to a large extent. Volume diffusion is extremely small at $1300{ }^{\circ} \mathrm{C}$ with grain boundary diffusion being the dominant process in CVD-SiC. 


\section{Acknowledgements}

Financial support of the National Research Foundation and the Bundesministerium für Bildung und Forschung is gratefully acknowledged. Thanks are due to Gerald Lenk from the Institut für Festkörperphysik, Friedrich-Schiller-Universität Jena, for the implantations.

\section{References}

[1] D. Hanson, A Review of Radionuclide Release from HTGR Cores During Normal Operation, Electric Power Research Institute, Report 1009382, March 2004.

[2] National Hydrogen Energy Roadmap, United States Department of Energy, Washington, DC, November 2002.

[3] A. Audren, A. Benyagoub, L. Thomé, F. Garrido, Nucl. Instrum. and Meth. B 257 (2007) 277.

[4] E. Friedland, N.G. van der Berg, J.B. Malherbe, R.J. Kuhudzai, A.J. Botha, E. Wendler, W. Wesch, Nucl. Instrum. and Meth. B 268 (2010) 2892.

[5] J.F. Ziegler, J.P. Biersack, U. Littmark, "The Stopping and Ranges of Ions in Solids", Pergamon Press, New York (1985).

[6] R. Devanathan, W.J. Weber, F. Gao, J. Appl. Phys. 90 (2001) 2303.

[7] S.M. Myers, S.T. Picraux, T.S. Prevender, Phys. Rev. B 9 (1974) 3953.

[8] E. Wendler, A. Heft, W. Wesch, Nucl. Instrum. and Meth. B 141 (1998) 105.

[9] L.L. Snead, S.J. Zinkle, Nucl. Instrum. and Meth. B 191 (2002) 497.

[10] E. Friedland, N.G. van der Berg, J.B. Malherbe, E. Wendler, W. Wesch, J. Nucl. Mater. 410 (2011) 24.

[11] R. Förthmann, E. Gyarmati, J. Nucl. Mater. 58 (1975) 189. 


\section{Figure Captions}

Fig. 1: RBS-channelling spectra of strontium implants in $6 \mathrm{H}-\mathrm{SiC}$ at different implantation temperatures $\mathrm{T}_{\mathrm{i}}$.

Fig. 2: Experimental strontium and iodine depth profiles implanted in $6 \mathrm{H}-\mathrm{SiC}$ at $\mathrm{RT}(\mathrm{X})$ and $600{ }^{\circ} \mathrm{C}(\mathrm{O})$ compared with TRIM-98 simulations.

Fig. 3: Profile widths of strontium implantations at $\mathrm{RT}$ in $6 \mathrm{H}-\mathrm{SiC}$ and at $600{ }^{\circ} \mathrm{C}$ in CVD$\mathrm{SiC}$ after isochronal annealing for 5 hours at temperatures up to $1400{ }^{\circ} \mathrm{C}$.

Fig. 4: Depth profiles of strontium implantations at $\mathrm{RT}$ in $6 \mathrm{H}-\mathrm{SiC}$ and at $600{ }^{\circ} \mathrm{C}$ in $\mathrm{CVD}-$ $\mathrm{SiC}$ after isochronal annealing for 5 hours at temperatures up to1400 ${ }^{\circ} \mathrm{C}$.

Fig. 5: Isothermal annealing curves for 6H-SiC (A) and CVD-SiC (B) implanted with strontium at $\mathrm{RT}$ and $600{ }^{\circ} \mathrm{C} . \mathrm{T}_{\mathrm{i}}$ and $\mathrm{T}_{\mathrm{a}}$ refer to implantation and annealing temperatures respectively.

Fig. 6: SEM images of strontium implants in CVD-SiC at $600{ }^{\circ} \mathrm{C}$ (a) and at RT (b) after 5 hours annealing at $1200{ }^{\circ} \mathrm{C}$ and $1000{ }^{\circ} \mathrm{C}$ respectively. The image at the bottom (c) depicts the surface of the RT implant after 60 hours annealing at $1200{ }^{\circ} \mathrm{C}$

Fig. 7: Depth profiles of iodine implantations at RT in 6H-SiC (A) and CVD-SiC (B) after isochronal annealing for 5 hours at temperatures up to $1300{ }^{\circ} \mathrm{C}$.

Fig. 8: Isothermal annealing curves at $1100{ }^{\circ} \mathrm{C}$ and $1200{ }^{\circ} \mathrm{C}$ for $\mathrm{RT}$ iodine implanted into CVD-SiC and $6 \mathrm{H}-\mathrm{SiC}$.

Fig. 9: Depth profiles of iodine implant in CVD-SiC at $600{ }^{\circ} \mathrm{C}$ before and after isochronal annealing for 5 hours at temperatures of $1200{ }^{\circ} \mathrm{C}$ and $1300{ }^{\circ} \mathrm{C}$.

Fig. 10: Isothermal annealing curves at $1200{ }^{\circ} \mathrm{C}$ and $1300{ }^{\circ} \mathrm{C}$ for iodine implanted at $600{ }^{\circ} \mathrm{C}$ into $6 \mathrm{H}-\mathrm{SiC}$ and CVD-SiC. 


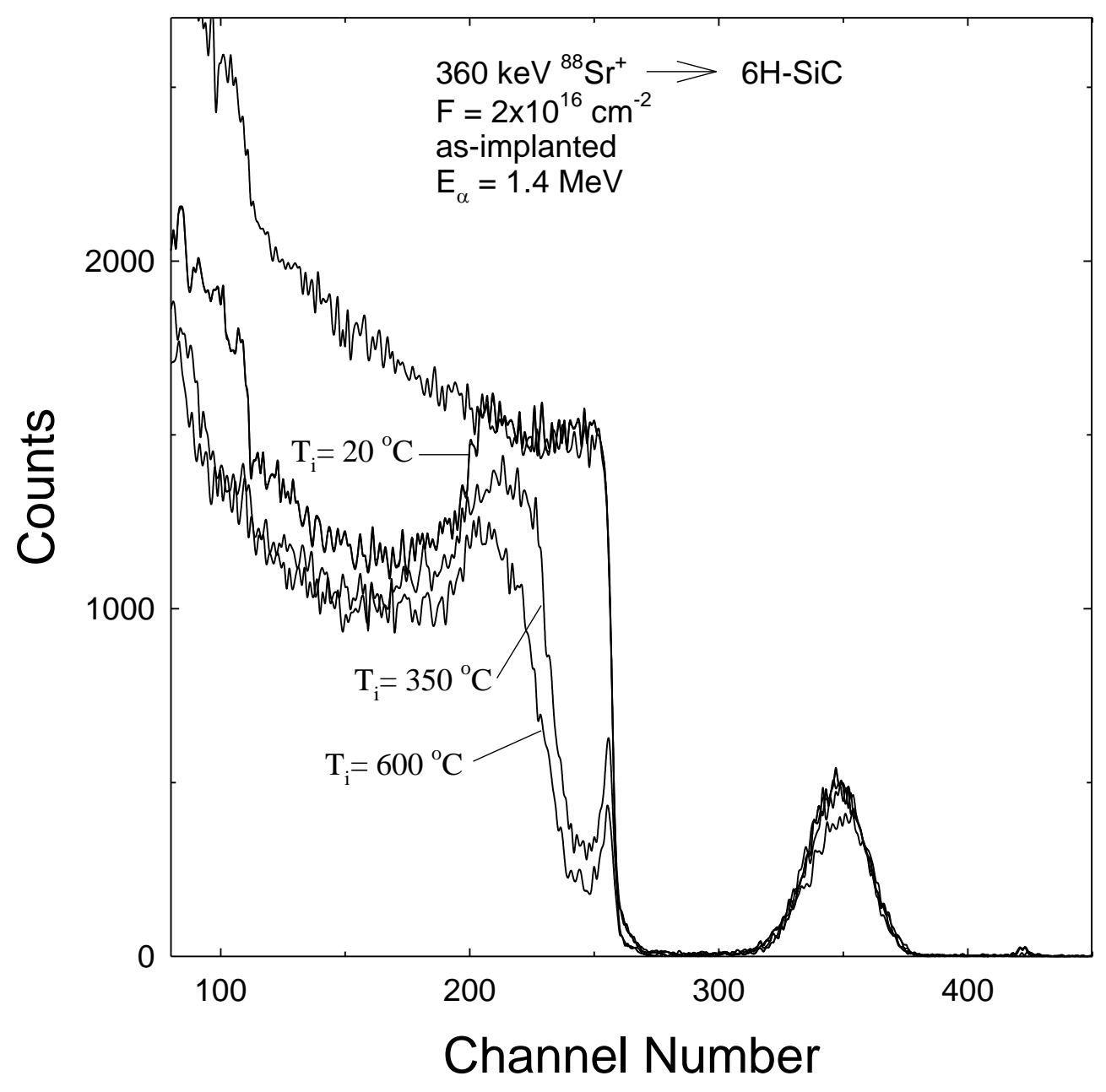

Figure 1 

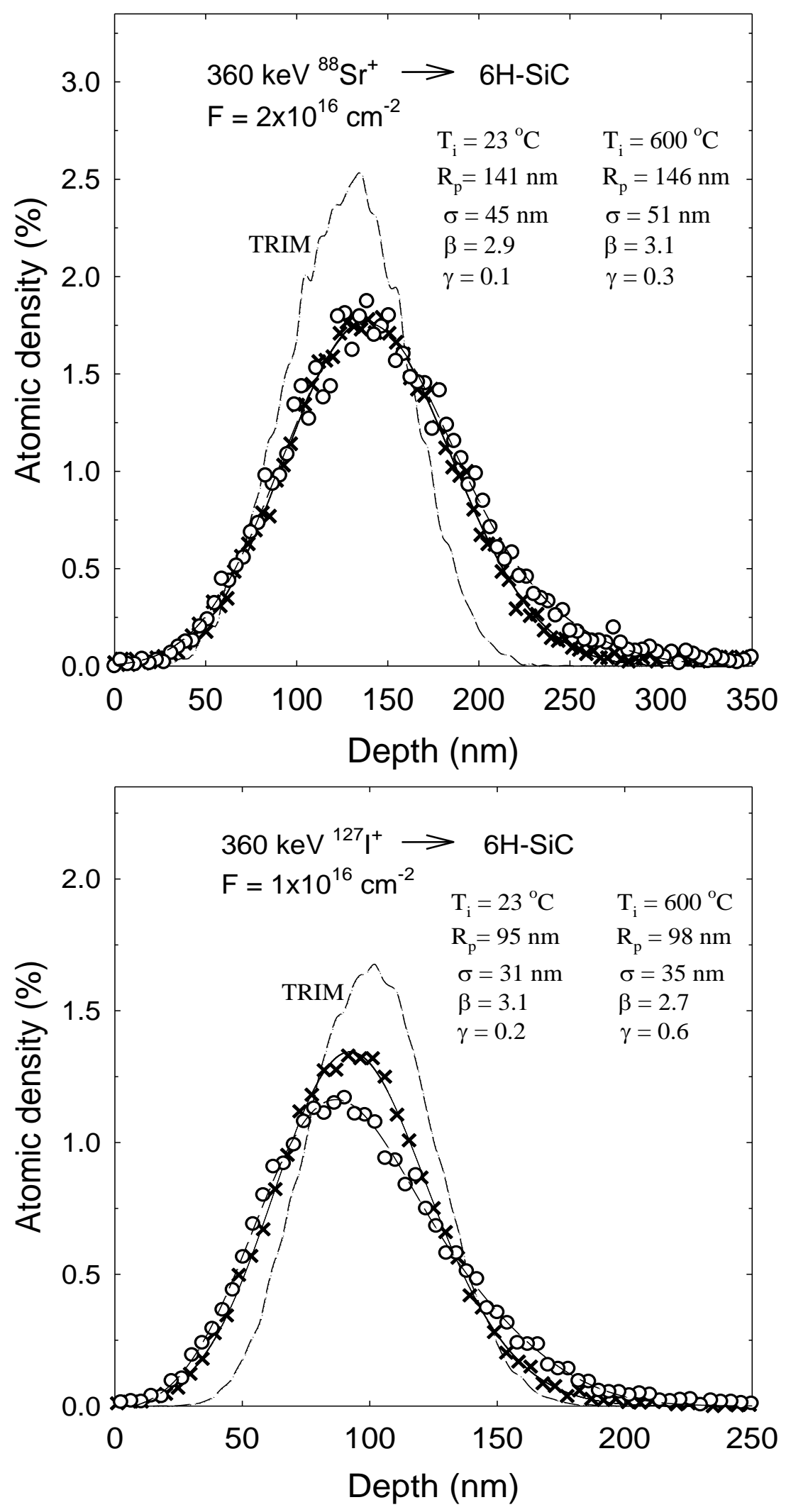

Figure 2 


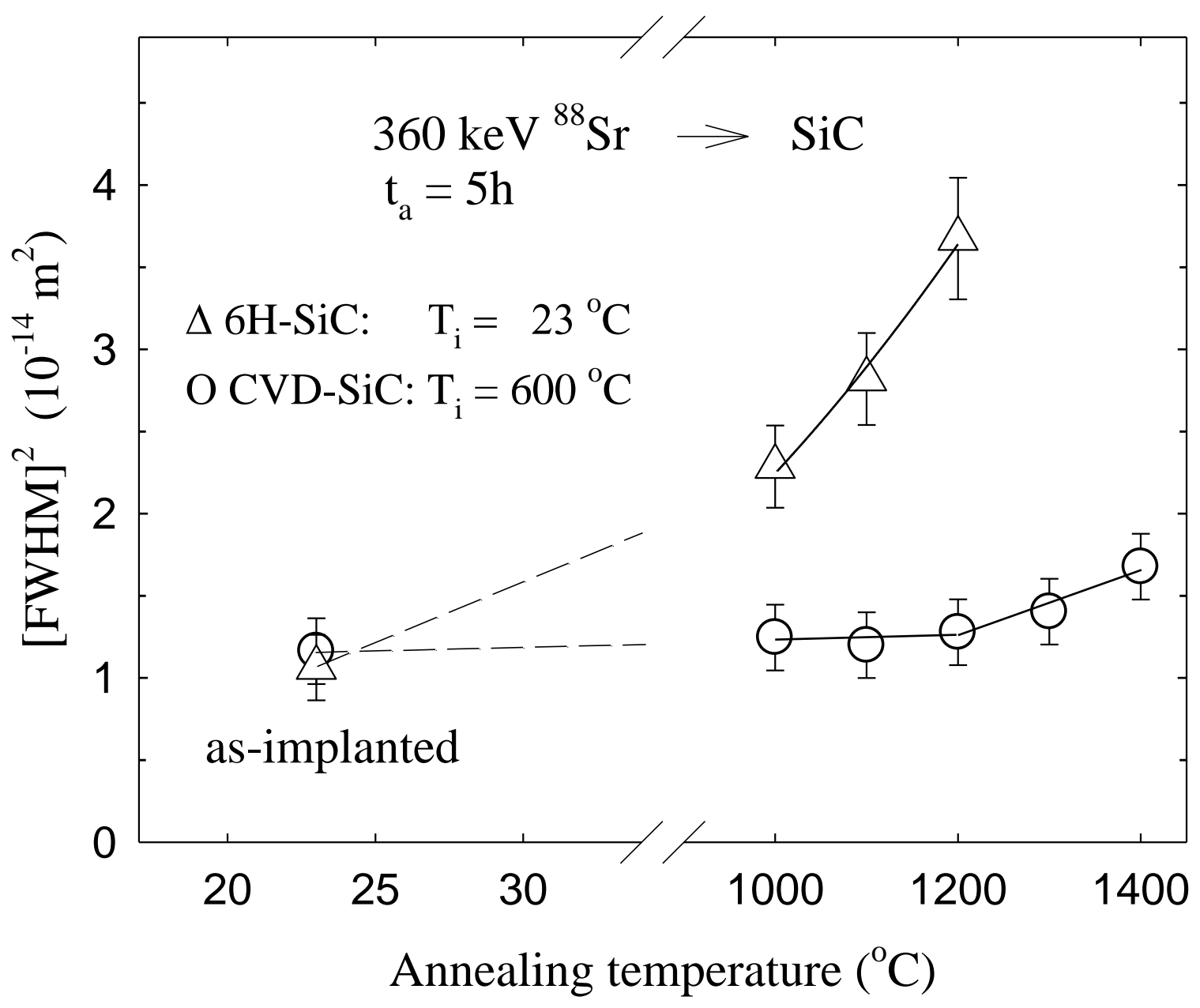

Figure 3 

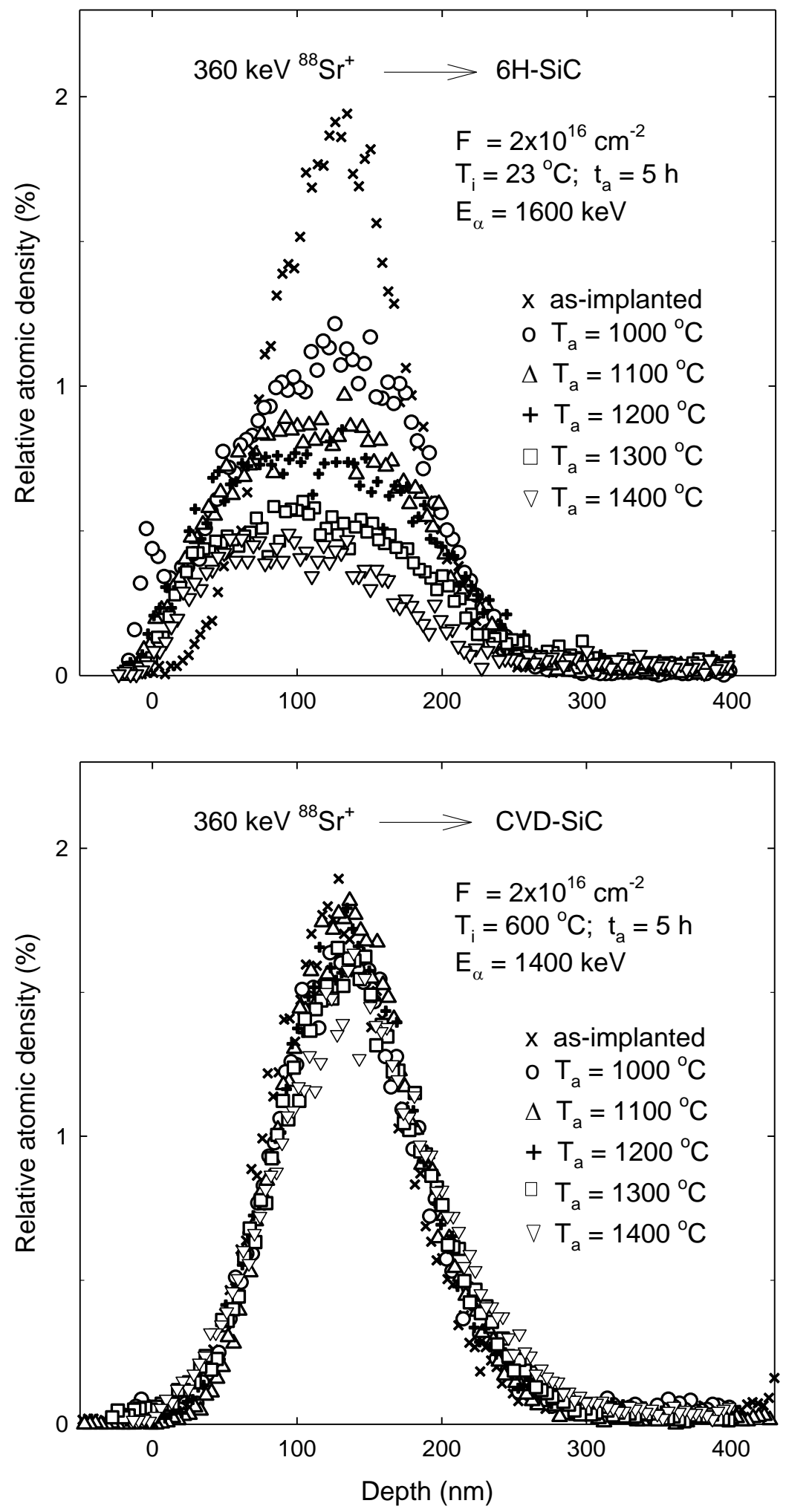

Figure 4 


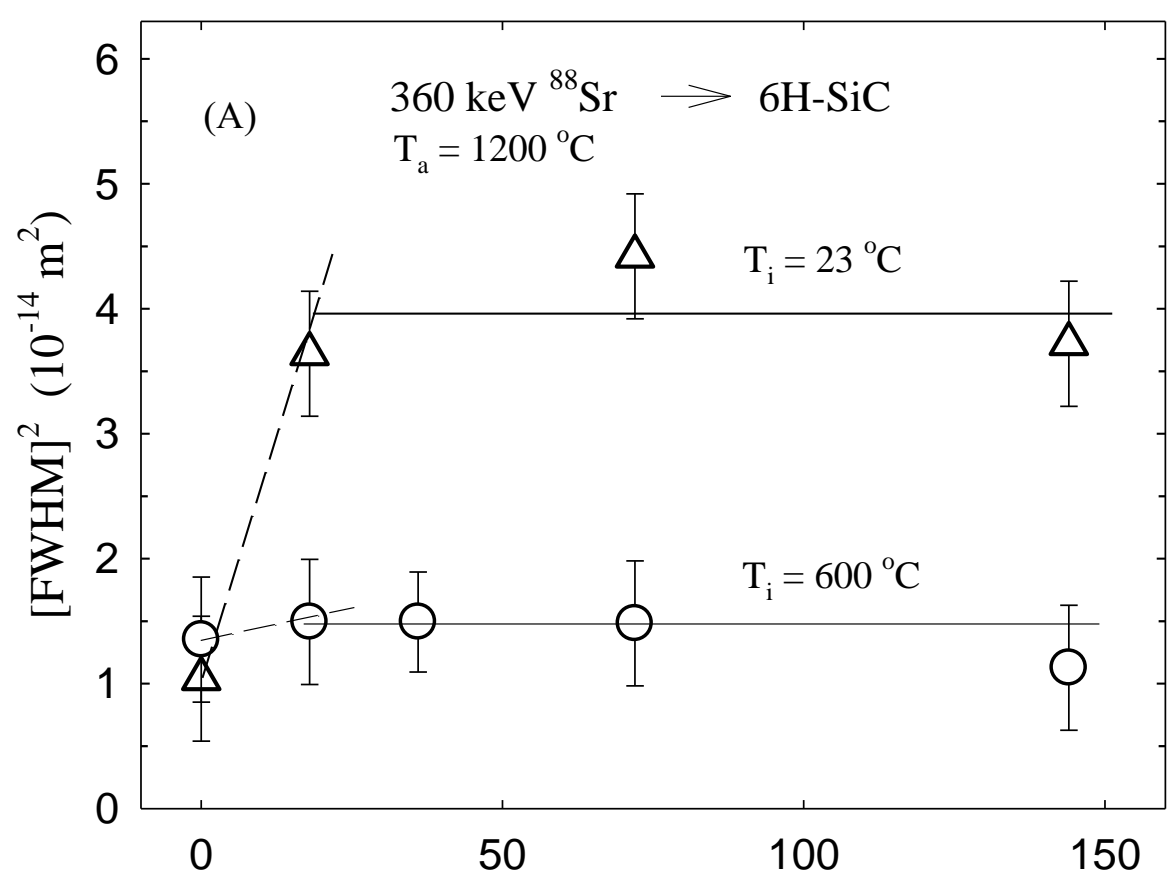

Annealing time $\left(10^{3} \mathrm{~s}\right)$

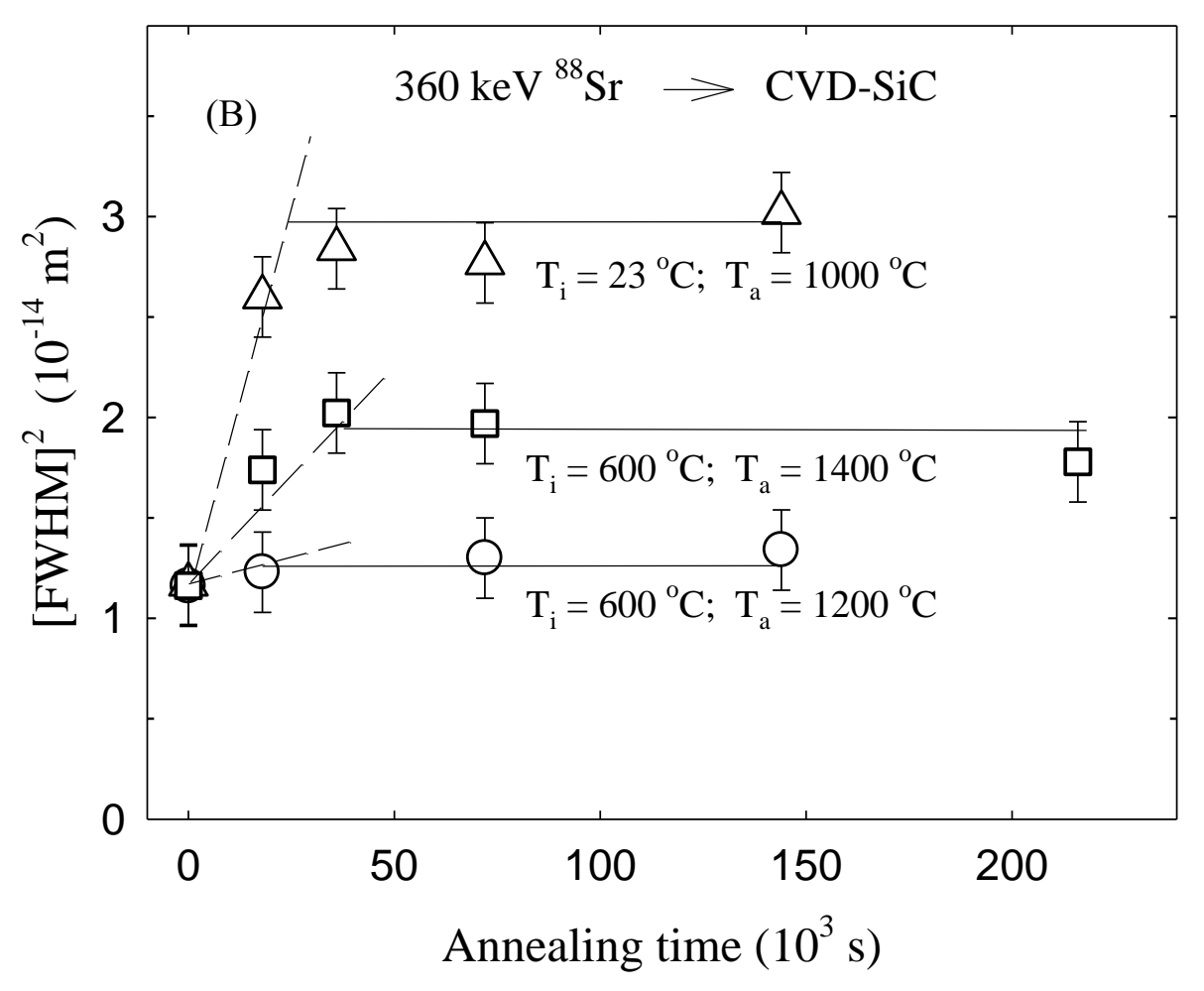

Figure 5 

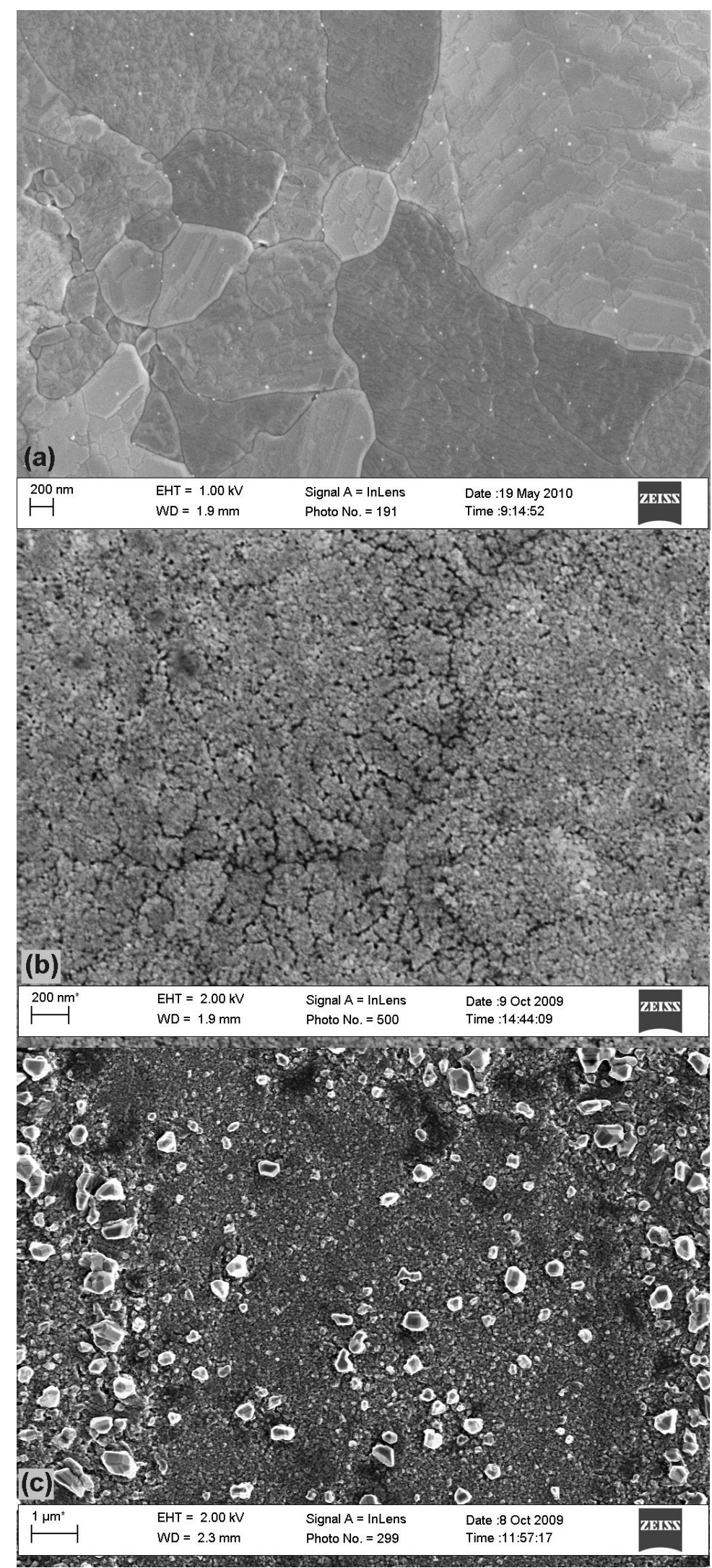

Figure 6 

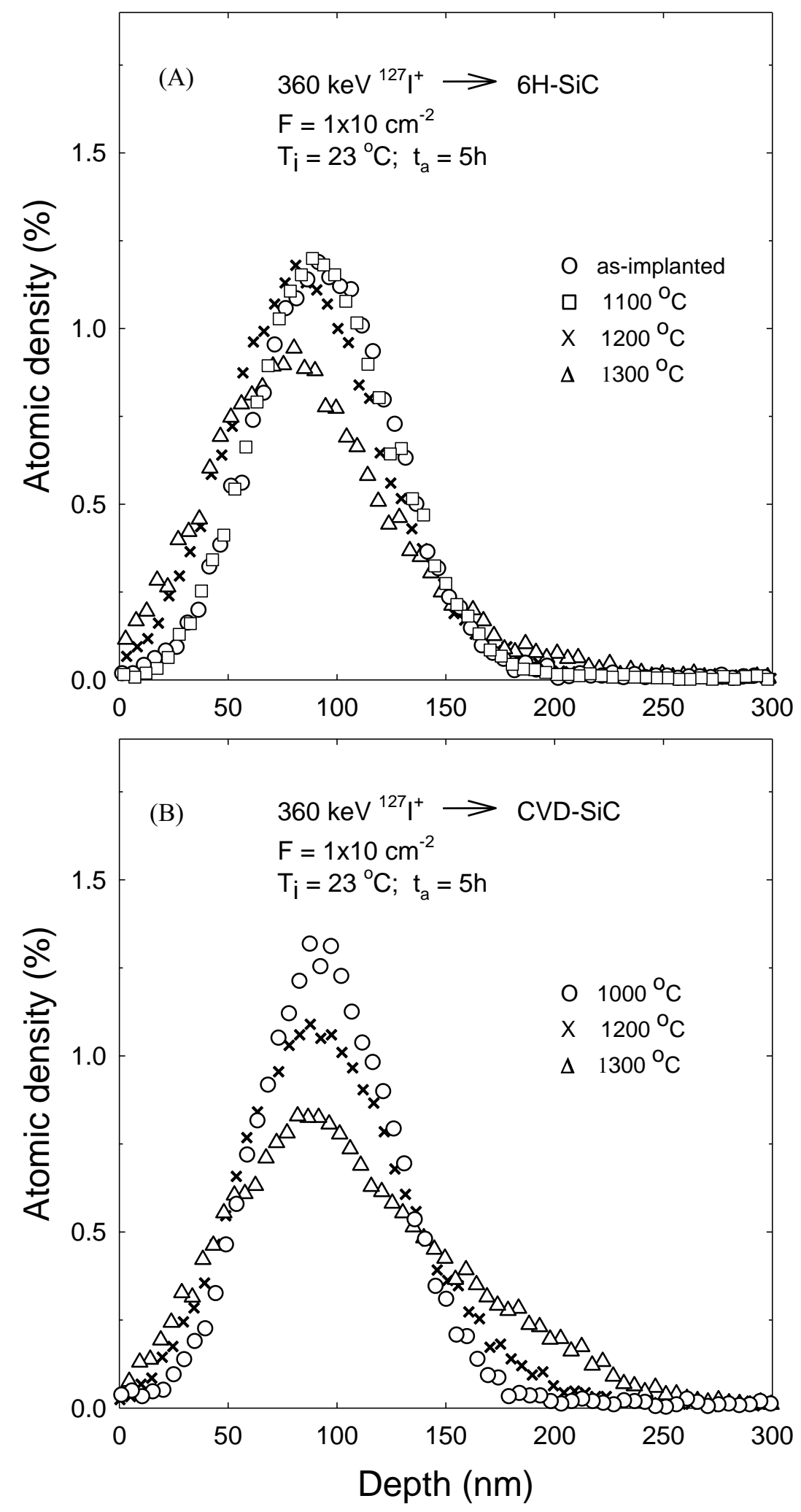

Figure 7 


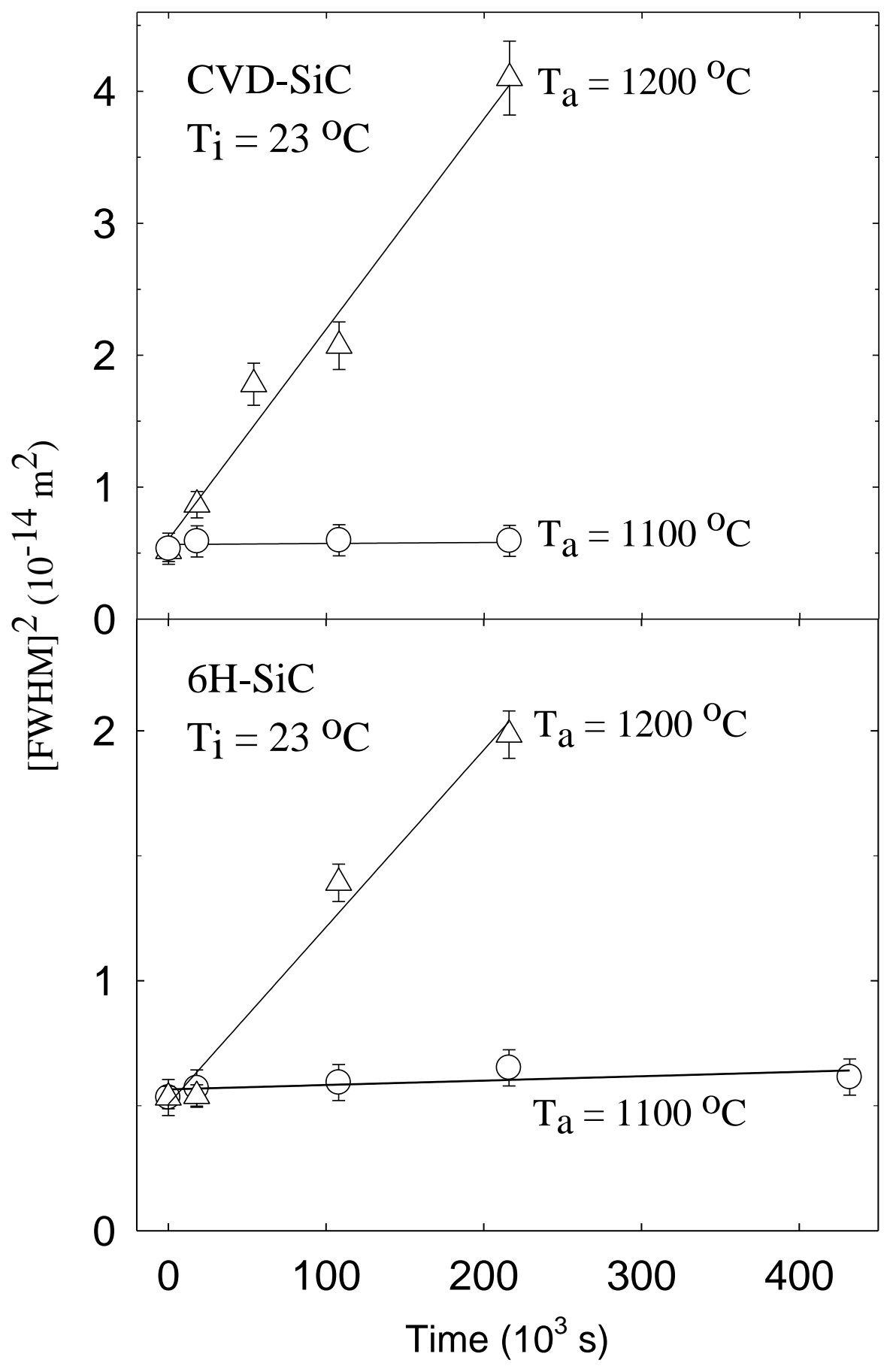

Figure 8 


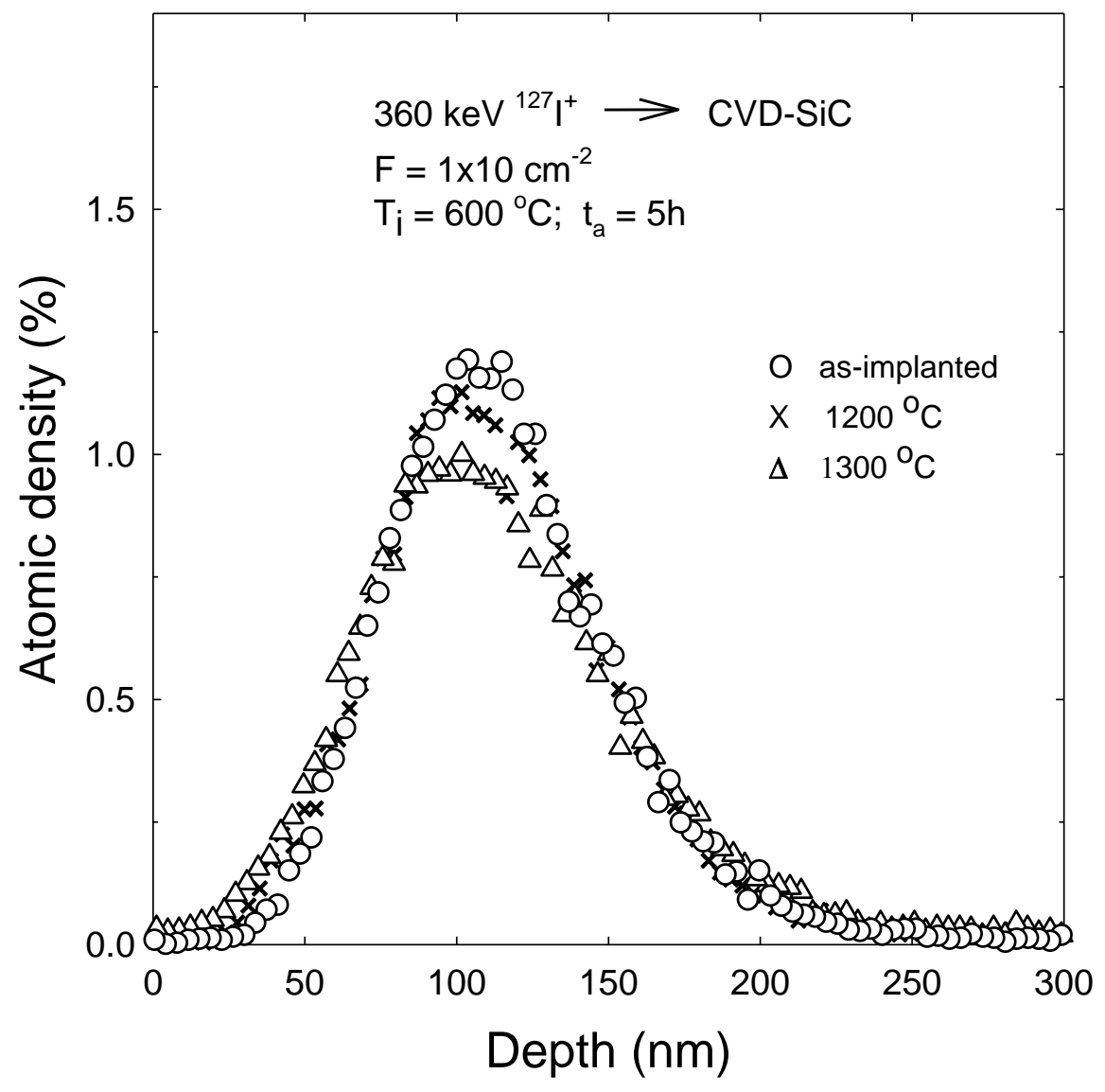

Figure 9 


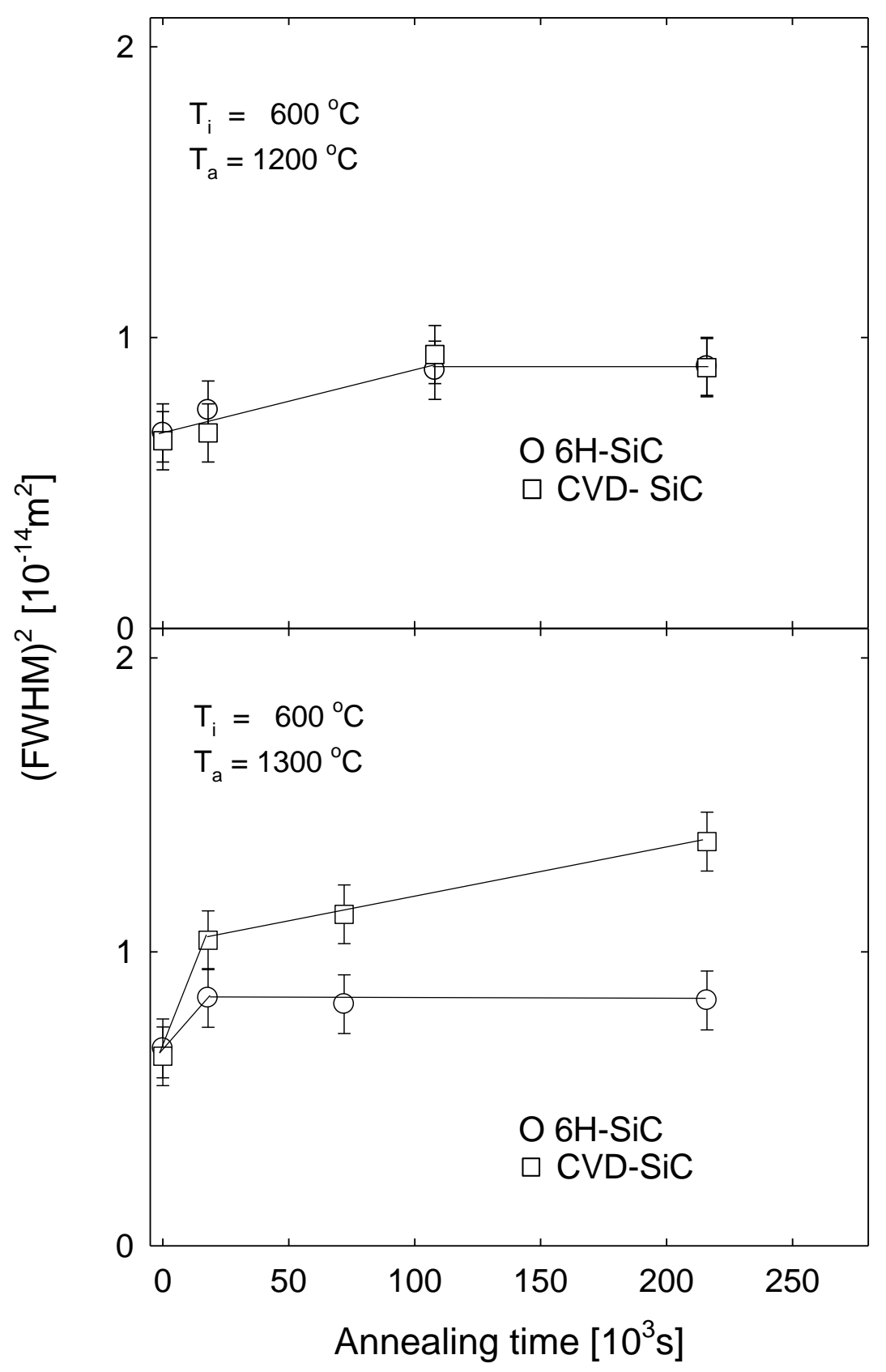

Figure 10 